\title{
Switching from complete to incomplete information
}

Citation for published version (APA):

Bochet, O. L. A. (2005). Switching from complete to incomplete information. METEOR, Maastricht University School of Business and Economics. METEOR Research Memorandum No. 037 https://doi.org/10.26481/umamet.2005037

Document status and date:

Published: 01/01/2005

DOI:

10.26481/umamet.2005037

Document Version:

Publisher's PDF, also known as Version of record

\section{Please check the document version of this publication:}

- A submitted manuscript is the version of the article upon submission and before peer-review. There can be important differences between the submitted version and the official published version of record.

People interested in the research are advised to contact the author for the final version of the publication, or visit the DOI to the publisher's website.

- The final author version and the galley proof are versions of the publication after peer review.

- The final published version features the final layout of the paper including the volume, issue and page numbers.

Link to publication

\footnotetext{
General rights rights.

- You may freely distribute the URL identifying the publication in the public portal. please follow below link for the End User Agreement:

www.umlib.nl/taverne-license

Take down policy

If you believe that this document breaches copyright please contact us at:

repository@maastrichtuniversity.nl

providing details and we will investigate your claim.
}

Copyright and moral rights for the publications made accessible in the public portal are retained by the authors and/or other copyright owners and it is a condition of accessing publications that users recognise and abide by the legal requirements associated with these

- Users may download and print one copy of any publication from the public portal for the purpose of private study or research.

- You may not further distribute the material or use it for any profit-making activity or commercial gain

If the publication is distributed under the terms of Article $25 \mathrm{fa}$ of the Dutch Copyright Act, indicated by the "Taverne" license above, 


\title{
Switching from Complete to Incomplete Information*
}

\section{Olivier Bochet ${ }^{\dagger}$}

\begin{abstract}
We construct an elementary mechanism (Dutta, Sen and Vohra (1995)) that Nash implements the Constrained Walrasian correspondence. We extend it to incomplete and non-exclusive information economies by enlarging the message space of agents. We characterize the set of Bayesian equilibrium outcomes of the mechanism, and thus characterize an extension of the Constrained Walrasian correspondence when one switches from complete to incomplete information. First, measurability restrictions on allocations do not emerge from the strategic behavior of agents: there exist simple economies for which the set of Constrained Rational Expectations equilibrium allocations is not contained in the set of equilibrium outcomes of the mechanism. Next, by imposing measurability restrictions on allocations, the mechanism globally implements the Constrained Rational Expectations Equilibrium correspondence. This result shows game-theoretic connections between these two market equilibrium concepts. However, it is obtained at the price of strong restrictions on the behavior of agents.

Keywords: Implementation, elementary mechanism, Walrasian equilibrium, Rational Expectations equilibrium.

*This paper is based on chapter 1 of my Phd dissertation completed at Brown University. I am grateful, without implicating, to Roberto Serrano, Rajiv Vohra, Herakles Polemarchakis and Enrico Minelli for helpful comments. I also thank seminar participants at Brown University, University of Melbourne, University of Namur, University of Essex, CSEF and University of Salerno for helpful comments. All errors are mine. Contact: o.bochet@algec.unimaas.nl

${ }^{\dagger}$ Maastricht University and CORE.
\end{abstract}




\section{Introduction}

The goal of implementation theory is to design institutions that eliminate strategic manipulations on part of the agents in order to implement desirable allocation rules. For instance, suppose a planner is interested in implementing Walrasian allocations. Some characteristics of the economy being unknown to her (e.g., preferences), her task is to provide adequate incentives to the agents so that, given an appropriate solution concept, every equilibrium outcome of the mechanism is a Walrasian allocation.

Using an implementation approach, we want to understand the connections between (constrained) Walrasian Equilibrium and (constrained) Rational Expectations Equilibrium (henceforth CWE and CREE, respectively). ${ }^{12}$ Palfrey and Srivastava (1987) show that in economies with non-exclusive information, risk-averse agents, strictly positive and state-independent endowments, the REE correspondence is globally implementable in Bayesian equilibrium. Wettstein (1990) constructs a continuous mechanism that implements CREE allocations in Bayesian equilibrium in non-exclusive information environments. However, in contrast with Bayesian implementation literature, the play of his game does not take place entirely at the interim stage. Both papers restrict attention to economies with non-exclusive differential information (henceforth NEI). Blume and Easley (1990) show that if NEI is not satisfied, one can construct a robust example of an economy with a unique REE that is not incentive-compatible. Hence, we consider non-exclusive differential information environments.

Our work is related to papers on implementation of WE and REE. However, our approach is different. We start by designing a mechanism that implements CWE allocations in Nash equilibrium. Our construction falls in the attractive class of elementary mechanisms, as defined in Dutta, Sen and

\footnotetext{
${ }^{1}$ See, for instance, Radner (1979).

${ }^{2}$ The difference between Walrasian equilibria (respectively Rational expectations equilibria) and Constrained Walrasian equilibria (respectively Constrained Rational expectations equilibria) is that in the latter, agents maximize their utility with respect to constrained budget sets which exclude bundles that exceed the aggregate endowment. As a consequence, every Walrasian equilibrium (respectively Rational expectations equilibrium) is a Constrained Walrasian equilibrium (respectively Constrained Rational expectations equilibria) but the converse is obviously not true.
} 
Vohra (1995), and is very similar to their construction. ${ }^{34}$ Elementary mechanisms are an answer to what sort of message spaces are needed in order to implement the (constrained) Walrasian correspondence. The mechanism we use is based on the Walrasian notion of allocation and prices and fits the Walrasian story. The question that comes to mind is how this mechanism - that performed well for a particular information structure and for a large class of economies- would work in differential information economies? This approach has been followed in a context different than ours by Dubey, Geanakopolos and Shubik (1987), Forges and Minelli (1997), or more recently Codognato and Ghosal (2003). These authors extend the well-known Shapley-Shubik strategic market games (see Shapley and Shubik (1977)) to differential information economies. ${ }^{5}$ In particular, Forges and Minelli (1997) obtain that when there is a continuum of agents of finitely many types -and some other assumptions-, REE can be obtained as particular communication equilibria of the Shapley-Shubik market game. ${ }^{6}$ A different line of research on decentralized trading procedures studies also the game-theoretic connections between WE and REE, and the strategic foundations of REE. For instance, see Gale (1987), Wolinsky (1990), or more recently Serrano (2002) as well as Gottardi and Serrano (2005). ${ }^{7}$

The question of the game-theoretic connections between WE and REE and the strategic foundations of REE is of importance. In fact, the extension of the concept of WE to the case of incomplete information is not yet fully understood. REE has been proposed as an extension and counterpart of the notion of competitive equilibrium to economies with differential information. ${ }^{8}$ It is the purpose of this paper -like the ones cited above- to try to understand the game-theoretic connections between these two market equilibrium

\footnotetext{
${ }^{3}$ It is well-known that the Walrasian correspondence violates in general Maskin monotonicity (Maskin, 1999), a necessary condition for Nash implementation when corner allocations are possible. Instead of restricting the domain of economies and ruling out corner Walrasian allocations, we consider the Constrained Walrasian correspondence.

${ }^{4}$ Thereafter, we will make use of DSV to refer to Dutta, Sen and Vohra (1995).

${ }^{5}$ Dubey, Geanakopolos and Shubik use a bids-offers market game while Forges and Minelli use a bids only market game. Codognato and Ghosal use a variant of the bids only market game in which it is not assumed that one specific commodity is used as money.

${ }^{6}$ Formally, the class of communication equilibria they study is called Self-fulfilling equilibria.

${ }^{7}$ Although his model deals with a situation of complete information, his results extends to differential economies with private values.

${ }^{8}$ See Radner (1979), among others.
} 
concepts. In our context, by extending an elementary mechanism to differential information settings, we would like to provide an answer to the following questions:

1) What is the extension of the set of equilibrium outcomes that one obtains in that case?

2 ) Is the extension related to the concept of competitive equilibrium?

3) Is the set of CREE allocations - at least- a subset of the set of Bayesian equilibrium outcomes?

4) Is it possible to obtain -and under what conditions- the CREE correspondence as an extension of the CWE correspondence?

We extend our mechanism from complete to incomplete information by enlarging the message space of agents. We characterize the set of Bayesian equilibrium outcomes of the extended mechanism and thus propose an extension of the Walrasian correspondence for differential information economies. We find that equilibrium allocation rules are expected utility maximizing over (constrained) state-contingent budget sets generated by prices reported by agents and individual endowments. The first main result of the paper shows that despite its similitude with WE and REE, the set of Bayesian Equilibrium outcomes of the mechanism does not always contain the set of CREE allocations. $^{9}$ Incorporating measurability of allocations with respect to prices, in the outcome function, imposes strong restrictions on the behavior of agents. By doing so, the mechanism globally implements the Constrained REE correspondence. This shows that connections between CWE and CREE can be obtained. However, the impact of this result is mitigated by the strong restrictions incorporated in the outcome function.

The plan of the paper is the following. In section 2, we present the model and the result for complete information as a benchmark for the understanding of section 3. In section 3, we extend the presentation of the model to economies with differential information and present the main results. Finally, we provide some final comments in section 4.

\section{Complete Information}

Before presenting the main results, we first introduce the mechanism as a benchmark for the next section. The mechanism we use falls in the class

\footnotetext{
${ }^{9}$ Namely, there exists economies for which the set of CREE allocations is not achievable as Bayesian equilibrium outcome of the mechanism.
} 
of elementary mechanisms defined by DSV (1995). Elementary mechanisms require the minimum amount of information necessary in order to implement allocations that are always - at least- efficient. We first describe the class of exchange economies we consider. We then briefly recall the definition of a game form and of a Nash equilibrium.

There a $l$ infinitely divisible goods and a set of agents $N=\{1, \ldots, n\}$, $n \geq 3$. The consumption set of each agent $i \in N$ is $X_{i}=\mathbb{R}_{+}^{l}$. Preferences of each agent $i \in N$ is represented by a utility function $u_{i}: X_{i} \rightarrow \mathbb{R}$. The endowment of each agent $i \in N$ is ${ }^{10} \omega_{i}>0$. The aggregate endowment is denoted by $\bar{\omega} \gg 0$.

The only characteristics unknown to the planner are the utility functions. Individual endowments and the consumption sets of agents are known and fixed. Hence, only the preferences of agents vary. An economy $E$ is simply a profile of utility functions, one for each agent. More formally, $E=\left(u_{i}\right)_{i \in N}$. Denote by $\mathcal{E}$ the class of economies in which, for each agent $i \in N, u_{i}$ is continuous, strictly increasing and quasi-concave.

A (feasible) allocation is a list of bundles $x=\left(x_{i}\right)_{i \in N} \in \mathbb{R}_{+}^{\ln }$ such that $\sum x_{i} \leq \bar{\omega}$. Formally, the set of feasible allocations is,

$$
A=\left\{x \in \mathbb{R}_{+}^{\ln }: \sum_{i \in N} x_{i} \leq \bar{\omega}\right\}
$$

Define $P=\mathbb{R}_{++}^{l}$ to be the set of strictly positive price vectors. For each agent $i \in N$, denote by $B_{i}(p) \subseteq X_{i}$ the budget set at a given price $p$.

$$
B_{i}(p)=\left\{x_{i} \in X_{i} \mid p \cdot x_{i} \leq p \cdot \omega_{i}\right\} .
$$

We denote by $\left.B_{i}(p)\right|_{x_{i} \leq \bar{\omega}}$ the constrained budget set of agent $i$ at $p$, that is the set of bundles that are both in the budget set $B_{i}(p)$ and that do not exceed the aggregate endowment $\bar{\omega}$.

Definition 1: A constrained Walrasian equilibrium is a pair $\left(p^{*}, x^{*}\right) \in$ $\mathbb{R}_{+}^{l} \times \mathbb{R}_{+}^{\ln }$ with $\sum_{i} x_{i}^{*}=\bar{\omega}$ and such that for each $i \in N, x_{i}^{*} \in \underset{\left.x_{i} \in B_{i}\left(p^{*}\right)\right|_{x_{i}<\bar{\omega}}}{\arg \max } u_{i}$

A normal game form or mechanism is defined as $\Gamma=(M, g)$, where $M=$ $\prod_{i} M_{i}$ is the message space and $g: M \rightarrow A$, is an outcome function that associates a feasible allocation with each path of play. Fixing the game

\footnotetext{
${ }^{10}$ We will order vectors with the ususal conventions $\gg,>, \geq$.
} 
$(\Gamma, E)$, the payoff that each player $i \in N$ receives after $m$ being played is $u_{i}\left(g(m)^{i}\right)$. A Nash equilibrium of $(\Gamma, E)$ is a strategy profile $m^{*} \in M$ such that for every $i \in N$

$$
u_{i}\left(g\left(m^{*}\right)^{i}\right) \geq u_{i}\left(g\left(m_{i}^{\prime}, m_{-i}^{*}\right)^{i}\right) \forall m_{i}^{\prime} \in M_{i} .
$$

The set of Nash equilibrium outcomes of $(\Gamma, E)$ is denoted $N E(\Gamma, E)$. The set of CWE allocations of a given economy $E$ is denoted $C W(E)$. A normal game form $\Gamma$ is said to implement in Nash equilibrium the constrained Walrasian correspondence if

$$
N E(\Gamma, E)=C W(E) \forall E \in \mathcal{E} .
$$

We are now ready to define the mechanism we use.

\section{The mechanism $\Gamma$ :}

Agents simultaneously announce the triple ${ }^{11}(x, p, n)^{i} \in A \times P \times \mathbb{N}$.

The outcome function is described as follows:

Rule 1: If for each $i \in N,(x, p)^{i}=(\bar{x}, \bar{p}), \bar{p} \cdot \bar{x}_{i}=\bar{p} \cdot \omega_{i} \forall i \in N$ and $\sum_{i} \bar{x}_{i}=\bar{\omega}$, then $\bar{x}$ is implemented.

Rule 2: If $(x, p)^{j}=(\bar{x}, \bar{p}) \forall j \neq i^{\star}$-where $i^{\star}=\min \left\{i \in N: n^{i} \geq n^{j} \forall j \in N\right\}-$ and if $(\bar{x}, \bar{p})$ satisfies the conditions presented in rule $1, p^{i^{\star}}=\bar{p}, x^{i^{\star}} \neq \bar{x}$, $\bar{p} \cdot x_{i^{\star}}^{i^{\star}}=\bar{p} \cdot \omega_{i^{\star}}$ and $x_{i^{\star}}^{i^{\star}} \leq \bar{\omega}$; then agent $i^{\star}$ gets $x_{i^{\star}}^{i^{\star}}$, the others $j \neq i^{\star}$ get 0 .

Rule 3: For all other cases, everybody receives their endowment, except agent $k^{\star}=\max \left\{k \in N: n^{k} \leq n^{j} \forall j \in N\right\}$ who receives 0 .

Notice that the mechanism is wasteful if agents do not agree on the report of a price and allocation. Indeed, in equilibrium, only rule 1 produces equilibrium outcome. The outcome function could be modified in order to be less wasteful. Doing so would complicate the analysis without adding any additional insights.

Proposition 1: The normal form mechanism $\Gamma$ implements the Constrained Walrasian correspondence in Nash Equilibrium in the class of economies $\mathcal{E}$.

Proof: See appendix.

\footnotetext{
${ }^{11}$ Where $\mathbb{N}$ is the set of positive integer.
} 


\section{REE as an extension of WE?}

\subsection{Extending the Model}

The structure is as in the previous section. Incomplete information is captured by the use of types. Denote by $T_{i}$ the finite set of types of player $i$. $T_{-i}=\prod_{j \neq i} T_{j}$ is the Cartesian product of the set of types of players other than player $i$. Define $T=\prod_{i} T_{i}$ to be the set of possible type profiles. We denote by $T^{\star} \subseteq T$ the set of states occurring with positive probability. A state of the world is a collection of types $t=\left(t_{1}, t_{2}, \ldots, t_{n}\right)$. A state summarizes agent's preferences and information. Thus preferences may vary across states and may be state dependent. Each agent has a prior probability distribution on states of the world $q_{i}$, defined on $T$. Obviously, agents agree on 0 probability states, i.e. if $q_{i}(t)=0$ for some $i \in N$, then $q_{j}(t)=0 \forall j \neq i$. The set of all such states is $T \backslash T^{\star}$. We make the following assumption on information structures.

Assumption 1: Information is non-exclusive $\forall t \in T^{\star}, \nexists t_{i}^{\prime} \in T_{i}$ with $t_{i}^{\prime} \neq t_{i}$ such that $t^{\prime}=\left(t_{1}, . ., t_{i-1}, t_{i}^{\prime}, t_{i+1}, . ., t_{n}\right) \in T^{\star}$.

Assumption 2: No redundant type.

$\forall i \in N, \forall t_{i} \in T_{i}, \exists t_{-i} \in T_{-i}$ such that $q_{i}\left(t_{i}, t_{-i}\right)>0$.

Consumptions sets and individual endowments are state-independent and known to the planner. Hence, the set of feasible allocation is constant across states. In the class of economies $\mathcal{E}$, only the utility functions and the type of the consumers vary. In $\mathcal{E}$, the Bernoulli utility function of each agent $i \in N$ in each state $t \in T, u_{i}(\cdot, t)$, continuous, strictly increasing and quasi-concave. More formally, $u_{i}: \mathbb{R}_{+}^{l} \times T \rightarrow \mathbb{R}_{+}$. An economy with differential information is defined as $E=\left\{\left(u_{i}, q_{i}, T_{i}\right)_{i \in N}\right\}$.

Definition 2: The environment is of private values if every agent is informationally autonomous. More formally,

$$
\forall i \in N, \forall t \in T, u_{i}(\cdot, t)=u_{i}\left(\cdot, t_{i}\right)
$$

Since information is non-exclusive, the mechanism can determine outcomes when the state reported is $s \notin T^{\star}$. In the mechanism, agents will be restricted to announce allocations over states occurring with positive probability. A (feasible) state-contingent allocation (over states occurring with 
positive probability) $x: T^{\star} \rightarrow A$ is a list of allocation, one for each state $t \in T^{\star}$, where $x=\left(x_{1}, x_{2}, \ldots ., x_{n}\right)$ such that $\sum x_{i}(t) \leq \bar{\omega}$ for each $t \in T^{\star}$. Denote by $\mathbf{A}$ the set of (ex-post) feasible state-contingent allocations defined over $T^{\star}$,

$$
\mathbf{A}=\left\{x: T^{\star} \rightarrow A\right\}
$$

Define by $\mathbf{P}$ the set of state-contingent strictly positive price vectors defined over states occurring with positive probability-, with element $p=$ $\left(p_{t}, p_{t^{\prime}}, \ldots\right)$. For every $i \in N$, denote by $B_{i}\left(p_{t}\right) \subseteq X_{i}$ the budget set of agent $i$, at a given price $p_{t}$.

$$
B_{i}\left(p_{t}\right)=\left\{x_{i} \in X_{i}: p_{t} \cdot x_{i} \leq p_{t} \cdot \omega_{i}\right\} .
$$

\section{Definition 3:}

Following Holmström-Myerson (1983), we recall the efficiency concepts useful for the paper.

- An allocation $x \in \mathbf{A}$ is ex-post efficient if there does not exist another allocation $y \in \mathbf{A}$ such that $u_{i}(y(t), t) \geq u_{i}(x(t), t) \forall i \in N$ and $\forall t$, with a strict inequality for at least one pair $(i, t)$.

- An allocation $x \in \mathbf{A}$ is interim efficient if there does not exist another allocation $y \in \mathbf{A}$ such that $U_{i}\left(y \mid t_{i}\right) \geq U_{i}\left(x \mid t_{i}\right) \forall i \in N, \forall t_{i} \in T_{i}$, with strict inequality for at least one pair $\left(i, t_{i}\right)$.

\section{Definition 4:}

A Constrained Rational Expectation Equilibrium (defined over states $t \in$ $\left.T^{\star}\right)$ is a pair $\left(p^{*}, x^{*}\right)$ such that:

1) $p_{t}^{*} \cdot x_{i}^{*}(t) \leq p_{t}^{*} \cdot \omega_{i} \forall t \in T^{\star}, \forall i \in N$

2) The final allocation is measurable with respect to the information that agents hold. That is, for every agent $i$ and every $t_{i}$ :

$$
p_{\left(t_{-i}, t_{i}\right)}^{*}=p_{\left(t_{-i}^{\prime}, t_{i}\right)}^{*} \Longrightarrow x_{i}^{*}\left(t_{-i}, t_{i}\right)=x_{i}^{*}\left(t_{-i}^{\prime}, t_{i}\right)
$$

3) $\sum_{t_{-i} \in T_{-i}} q_{i}\left(t_{-i} \mid t_{i}\right) u_{i}\left(x_{i}^{*}\left(t_{-i}, t_{i}\right), t_{i}\right) \geq \sum_{t_{-i} \in T_{-i}} q_{i}\left(t_{-i} \mid t_{i}\right) u_{i}\left(y_{i}\left(t_{-i}, t_{i}\right), t_{i}\right), \forall i \in$ $N, \forall t_{i} \in T_{i}$ and for every measurable $y_{i}$ such that $\left.y_{i}(t) \in B_{i}\left(p_{t}^{*}\right)\right|_{y_{i}(t) \leq \bar{\omega}} \forall t \in$ $T^{\star}$.

4) $\sum_{i \in N} x_{i}^{*}(t)=\bar{\omega} \forall t \in T^{\star}$.

Definition 5: A deception for agent $i$ is a mapping $\alpha_{i}: T_{i} \rightarrow T_{i}$. The interpretation is that when agent $i$ is of type $t_{i}$, he acts (or report) as if he was of type $\alpha_{i}\left(t_{i}\right)$. Notice that by the definition of $\alpha_{i}$, it is possible that 
$\alpha_{i}\left(t_{i}\right)=t_{i}$, i.e. agent $i$ reports truthfully her type. Truthtelling is just the identity mapping and is denoted $\hat{\alpha}$. We denote by $\alpha(t)=\left(\alpha_{1}\left(t_{1}\right), \ldots, \alpha_{n}\left(t_{n}\right)\right)$ a collection of deception strategies. Thus, a profile of deception generates the mapping $\alpha: T \rightarrow T$. Define $x_{\alpha}=x \circ \alpha=\left(x(\alpha(t)), x\left(\alpha\left(t^{\prime}\right)\right), \ldots\right)$; that is, $x \circ \alpha(t)=x(\alpha(t))$.

Definition 6: Define by $X=\{x: T \rightarrow A\}$ the set of all social choice functions. A social choice set $F$ is a subset of $X$. Since information is non-exclusive and the mechanism defines outcomes in the event that an incompatible report of a state $s \notin T^{\star}$ occurs, we restrict attention to $X^{\star}=$ $\left\{x: T^{\star} \rightarrow A\right\}$. In that case $X^{\star}=\mathbf{A}$.

Definition 7: A social choice correspondence $\mathcal{F}: \mathcal{E} \rightarrow 2^{X}$ defined on the domain $\mathcal{E}$ is a set-valued function which assigns to every economy $E$ in $\mathcal{E}$ a social choice set. $\mathcal{F}$ is said to be globally implementable in Bayesian equilibrium relative to $\mathcal{E}$ if, for all $E \in \mathcal{E}, \mathcal{F}(E)$ is Bayesian implementable. Again, we restrict attention to $\mathcal{F}^{\star}: \mathcal{E} \rightarrow 2^{X^{\star}}$ because of NEI.

The play of the game takes place at the interim stage. Agents know their own type. The interim expected utility of each agent $i \in N$, when of type $t_{i} \in T_{i}$, is

$$
U_{i}\left(\cdot \mid t_{i}\right)=\sum_{t_{-i} \in T_{-i}} q_{i}\left(t_{-i} \mid t_{i}\right) u_{i}\left(\cdot,\left(t_{-i}, t_{i}\right)\right)
$$

A game form, or mechanism, is an array $\Gamma=(M, g)$, where $M=\prod_{i} M_{i}$ is a message space and $g: M \rightarrow A$ an outcome function that associates a feasible bundle to each agent, for every profile of message $m \in M$ that is played. For each agent $i \in N$, the set $M_{i}$ is the set of all possible messages he can announce. The difference with the previous section is that each agent $i \in N$ chooses messages $m_{i}$ as a function of his types. We call a mapping $\sigma_{i}: T_{i} \rightarrow M_{i}$ a strategy for agent $i$ and $\Sigma_{i}$ his set of strategies. Given a strategy profile $\sigma=\left(\sigma_{1}, \ldots, \sigma_{n}\right)$ with $\sigma(t)=\left(\sigma_{1}\left(t_{1}\right), \ldots, \sigma_{n}\left(t_{n}\right)\right), g(\sigma)=$ $\left\{g\left(\sigma(t), g\left(\sigma\left(t^{\prime}\right), \ldots\right\}\right.\right.$ represents the allocation rule which results when $\sigma$ is played. Suppose the strategy profile $\sigma$ is played. Let $g(\sigma)^{i}$ stand for bundles obtained by consumer $i$ at the allocations prescribed by the path induced by $\sigma$, that is, $g(\sigma)$. Fixing the game $(\Gamma, E)$, the payoff that each player $i \in N$ receives after $\sigma$ being played is (ex-post), in state $t, u_{i}\left(g(\sigma(t))^{i}, t\right)$.

A Bayesian equilibrium of a game with incomplete information is a profile 
of strategies $\left(\left(\sigma_{i}\left(t_{i}\right)\right)_{i \in N, t_{i} \in T_{i}}\right)$, such that, for each $i \in N$, each $t_{i} \in T_{i}$,

$$
U_{i}\left(g(\sigma)^{i} \mid t_{i}\right) \geq U_{i}\left(g\left(\sigma_{i}^{\prime}, \sigma_{-i}\right)^{i} \mid t_{i}\right) \forall \sigma_{i}^{\prime} \in \Sigma_{i} .
$$

The set of Bayesian equilibrium outcomes of $(\Gamma, E)$ is denoted $B E(\Gamma, E)$. The set of CREE allocations of a given economy $E$ is denoted $C R E E(E)$. A normal game form $\Gamma$ is said to globally implement in Bayesian equilibrium the constrained REE correspondence if

$$
B E(\Gamma, E)=C R E E(E) \forall E \in \mathcal{E}
$$

\subsection{Extending the mechanism: achievability of CREE}

The message space of agents is enlarged to include report of private information, state-contingent allocations and prices for states occurring with positive probability. Since the environment is of non-exclusive information, incentive compatibility is indeed still a necessary condition but is vacuously satisfied. To see this, notice that we have to pay attention to the collection of types that are reported. Since $T^{\star} \subset T$, it is possible that the collective report of types is incompatible. The planner knows that if the agents collectively report state $t$, then $t$ is either in $T^{\star}$ or in $T \backslash T^{\star}$. An obvious feature of nonexclusive information environment is that if $t \in T^{\star}$ has been reported, then any unilateral deviation in type by an agent would result in an incompatible report $t^{\prime} \notin T^{\star}$. Since incompatible reports can be detected, incentive compatibility is easily satisfied. For instance, in case of an incompatible report, the planner may confiscate the aggregate endowment.

We briefly summarize some welfare properties and the nature of CREE defined over the class of economies $\mathcal{E}$. Examples can be found in the appendix: CREE allocations may not be ex-post individually rational, stateby-state- Walrasian or interim efficient. However, in private values environments, every CREE allocation is ex-post individually rational and state-bystate Walrasian.

The mechanism $\Gamma$ :

Agents simultaneously announce the quadruple $\left(x, p, n, t_{i}\right)^{i} \in \mathbf{A} \times \mathbf{P} \times$ $\mathbb{N} \times T_{i}$.

The outcome function is described as follows: 
Rule 1: If the collection of types reported $s$ is compatible com $^{12},(x, p)^{i}=$ $(\bar{x}, \bar{p}) \forall i \in N, \bar{p}_{t} \cdot \bar{x}_{i}(t)=\bar{p}_{t} \cdot \omega_{i} \forall i \in N, \forall t \in T^{\star}$ and $\sum_{i} \bar{x}_{i}(t)=\bar{\omega} \forall t \in T^{\star}$, then $\bar{x}(s)$ is implemented.

Rule 2: If the collection of types $s$ reported is compatible, if $(x, p)^{j}=$ $(\bar{x}, \bar{p}) \forall j \neq i^{\star}$ where $i^{\star}=\min \left\{i \in N: n^{i} \geq n^{j} \forall j \in N\right\}$ and if $(\bar{x}, \bar{p})$ satisfies the conditions presented in rule $1, p^{i^{\star}}=\bar{p}, x^{i^{\star}} \neq \bar{x}, \bar{p}_{t} \cdot x_{i^{\star}}^{i^{\star}}(t)=\bar{p}_{t} \cdot \omega_{i^{\star}} \forall t \in T^{\star}$ and $x_{i^{\star}}^{i^{\star}}(t) \leq \bar{\omega} \forall t \in T^{\star}$; then agent $i^{\star}$ gets $x_{i^{\star}}^{i^{\star}}(s)$, agents $j \neq i^{\star}$ get 0 (and the rest of the goods is thrown away).

Rule 3: For all other cases, everybody receives their endowment, except agent $k^{\star}=\max \left\{k \in N: n^{k} \leq n^{j} \forall j \in N\right\}$ who receives 0 .

We characterize the set of equilibrium outcomes. It is a natural extension of the set of equilibrium outcomes obtained for the complete information case. Suppose $\sigma$ is a Bayesian Equilibrium such that $\sigma_{i}\left(t_{i}\right)=\left(x, p, n, \alpha_{i}\left(t_{i}\right)\right)^{i}$ $\forall i \in N, \forall t_{i} \in T_{i}$ and $g(\sigma)=a$.

Proposition 2: The characterization of equilibrium outcomes is such that:

1) Every equilibrium outcome is given by rule 1 .

2) For every compatible deception $\alpha$ ( $\alpha=\hat{\alpha}$ or $\alpha \neq \hat{\alpha})$, for every agent, $\bar{x}_{\alpha}$ is expected-utility maximizing over the Constrained budget sets generated by $\bar{p}_{\alpha}$ and individual endowments.

3) Moreover, when the environment is of private values, $\bar{x}_{\alpha}$ is state-bystate Walrasian

Proof: The proof of the proposition is divided in a series of lemma. Lemma 4 and 5 prove the first part of the proposition. Lemma 6 and 7 prove respectively the second and third part of the proposition.

Lemma 4: For every $\alpha(\alpha=\hat{\alpha}$ or $\alpha \neq \hat{\alpha})$, there does not exists $t \in T^{\star}$ such that $a(\alpha(t))$ comes from rule 3

Proof: Suppose not. The deception $\alpha$ has been used, and for $\alpha(t)$ reported, the outcome $a(\alpha(t))$ is given by rule 3 . Agent $k^{\star}$, of type $t_{k^{\star}}$ receives 0 following the report $\alpha(t)$. Agent $k^{\star}$ can become agent $i^{\star}$ by appropriately announcing a different integer, and this with probability one, for every $\alpha(s)$ for which $\alpha_{k^{\star}}\left(s_{k^{\star}}\right)=\alpha_{k^{\star}}\left(t_{k^{\star}}\right)$. Call him agent $i^{\star}$, of type $t_{i^{\star}}$, following the deviation. For $\alpha(t)$ reported, if the outcome still falls in rule 3 following the

\footnotetext{
${ }^{12} \mathrm{~A}$ report of types $\left(s_{i}\right)_{i \in N}$ is said to be compatible if $s \in T^{\star}$.
} 
change in integer, agent $i^{\star}$ receives $\omega_{i^{\star}}$. Since $\omega_{i}>0 \forall i \in N$ and preferences are strongly monotonic, this is profitable when $\alpha(t)$ is reported. On the other hand, if the outcome now falls in rule 2 when $\alpha(t)$ is reported, this deviator is awarded $x_{i^{\star}}^{i^{\star}}$. Since $p_{\alpha(t)} \gg 0$ and $\omega_{i^{\star}}>0$, it is the case that $x_{i^{\star}}^{i^{\star}}>0$. By strong monotonicity of preferences, this is profitable when $\alpha(t)$ is reported. Now, for other $\alpha(s) \neq \alpha(t)$ with $\alpha_{i^{\star}}\left(s_{i^{\star}}\right)=\alpha_{i^{\star}}\left(t_{i^{\star}}\right)$, if $a(\alpha(s))$ was given by rule 2 , notice that agent $k^{\star}$ was receiving 0 unless he was agent $i^{\star}$ when $\alpha(s)$ was reported. In that case, $a(\alpha(s))$ is now given by rule 3 following the change in integer announced. Again this is profitable when $\alpha(s)$ is reported. Otherwise, if for $\alpha(s)$, agent $k^{\star}$ was in fact already agent $i^{\star}$, then the change in integer does not affect the outcome $a(\alpha(s))$. Finally, if $a(\alpha(s))$ was given by rule 1 , notice that a change in integer does not affect the outcome in such a case. Therefore, this is a deviation that is interim profitable. A contradiction with $m$ being a Bayesian Equilibrium.

A consequence of this lemma is that type-reports should always be compatible.

Lemma 5: For every compatible $\alpha(\alpha=\hat{\alpha}$ or $\alpha \neq \hat{\alpha})$, there does not exists $t \in T^{\star}$ such that $a(\alpha(t))$ comes from rule 2

Proof: Suppose not. The compatible $\alpha$ has been used and for $\alpha(t)$ reported, $a(\alpha(t))$ is given by rule 2 . Agent $j \neq i^{\star}$, of type $t_{j}$, receive the 0 bundle when state $\alpha(t)$ has been reported. By modifying her integer announced, she can become agent $i^{\star}$, the agent with the highest integer, with probability one, for any $\alpha(s)$ with $\alpha_{j}\left(s_{j}\right)=\alpha_{j}\left(t_{j}\right)$. So, call her agent $i^{\star}$, of type $t_{i^{\star}}$. Thus, given the rules of the game, the outcome is now given by rule 3 with probability one when $\alpha(t)$ is reported. Therefore, given $\alpha(t)$, agent $i^{\star}$ would receive $\omega_{i^{\star}}$ which dominates 0 , since $\omega_{i^{\star}}>0$ and preferences are strongly monotonic. For the other $\alpha(s) \neq \alpha(t)$ for which $\alpha_{i^{\star}}\left(s_{i^{\star}}\right)=\alpha_{i^{\star}}\left(t_{i^{\star}}\right)$, if the outcome was initially given by rule 2 , it is now either given by rule 3 -thus profitable- or still given by rule 2 if the new agent $i^{\star}$ was already $i^{\star}$ for the report $\alpha(s)$-and thus the outcome $a(\alpha(s))$ would remain unchanged-; or the outcome was given by rule 1 , in which case, the outcome is unaffected by a change in the integer announced. Therefore, this deviation is interim profitable. A contradiction.

A consequence of this lemma is that equilibrium outcomes are always given by rule 1 . In equilibrium, agents always agree on a state contingent price-allocation pair. 
Lemma 6: For every compatible $\alpha(\alpha=\hat{\alpha}$ or $\alpha \neq \hat{\alpha}), \forall i \in N, \forall t_{i} \in T_{i}$, $\bar{x}_{\alpha}=\bar{x} \circ \alpha$ is maximal ${ }^{13}$ in the budget sets generated by $\bar{p} \circ \alpha$ and $\omega_{i}$, and the feasibility constraints

Proof: Suppose not. The compatible $\alpha$ is used $(\alpha=\hat{\alpha}$ or $\alpha \neq \hat{\alpha})$ and there exists an agent $i$, of type $t_{i}$, with report $\alpha_{i}\left(t_{i}\right)$, an allocation $y \neq \bar{x}$, with $y_{i}(s) \leq \bar{\omega} \forall s \in T^{\star}, \bar{p}_{s} \cdot y_{i}(s)=\bar{p}_{s} \cdot \omega_{i} \forall s \in T^{\star}$, and such that,

$$
U_{i}\left(y_{\alpha} \mid t_{i}\right)>U_{i}\left(\bar{x}_{\alpha} \mid t_{i}\right) .
$$

Agent $i$, of type $t_{i}$ has a profitable deviation. She can modify the integer she announced so as to become agent $i^{\star}$, the agent with the highest integer, with probability one, and announce the state-contingent allocation $y \neq \bar{x}$. By the rules of the game, the outcome is given by rule 2. Therefore, given a collective report $\alpha(s)$, agent $i^{\star}$ is awarded $y_{i^{\star}}(\alpha(s))$; and this for every report $\alpha(s)$ for which $\alpha_{i^{\star}}\left(s_{i^{\star}}\right)=\alpha_{i^{\star}}\left(t_{i^{\star}}\right)$. Agent $i$, of type $t_{i}$, by playing this deviation, obtains the expected utility defined above. This is an interim profitable deviation. A contradiction.

Lemma 7: If the environment is of private values, then for every compatible $\alpha$ (with $\alpha=\hat{\alpha}$ or $\alpha \neq \hat{\alpha}$ ), and for every $\alpha(t) \in T^{\star}, \bar{x}(\alpha(t))$ is Constrained Walrasian at $t$, with price $\bar{p}_{\alpha(t)}$.

Proof: By the previous lemma, we already know that $\bar{x}_{\alpha}$ is expected utility maximizing over the budgets sets generated by individual endowments and $\bar{p}_{\alpha}$, and the feasibility constraints. Since the environment is of private values, for every agent $i$ of type $t_{i}$, for every $\alpha(s)$ for which $\alpha_{i}\left(s_{i}\right)=\alpha_{i}\left(t_{i}\right)$, $\bar{x}_{i}(\alpha(s)) \in \arg \max u_{i}\left(x_{i}, t_{i}\right)$ subject to $\left.B_{i}\left(\bar{p}_{\alpha(s)}\right)\right|_{x_{i} \leq \bar{\omega}}$. Therefore, for every compatible $\alpha,(\bar{x} \circ \alpha, \bar{p} \circ \alpha)$ is state-by-state Constrained Walrasian.

Q.E.D.

This lemma concludes the characterization of the set of equilibrium outcomes. In private values environments, every equilibrium allocation rule is state-by-state constrained Walrasian. The mechanism globally implements the social choice correspondence for which, for every economy $E \in \mathcal{E}$, the social choice set is composed of state-by-state CWE allocation rules. The set of Constrained state-by-state Walrasian allocations is in general a superset of the set of CREE allocations. The definition of CREE excludes

\footnotetext{
${ }^{13}$ That is, $\forall i, \forall t_{i} \in T_{i}, \bar{x}_{\alpha} \in \arg \max _{x_{i}} U_{i}\left(x \mid t_{i}\right)$ subject to $x_{i}(t) \leq \bar{\omega} \forall t \in T$, and the budget sets generated by $\bar{p}_{\alpha}$ and individual endowments.
} 
non-measurable allocations. However, a state-by-state Walrasian allocation may not be measurable. Measurability is very strong and not meaningful in private values settings. It excludes allocations with good welfare properties even though agents do not really care about the state of the world. However, assuming strict quasi-concavity of utility functions - as opposed to quasiconcavity - implies measurability of allocations with respect to prices ${ }^{14}$. The state-by-state Walrasian correspondence and the CREE correspondence then coincide.

For environments that do not satisfy private values, the allocation $\bar{x}_{\alpha}$ should be a maximal element in the budget sets generated by $\bar{p}_{\alpha}$ and individual endowments, subject to the feasibility constraints. In fact, in equilibrium in which agents are truthful, $(\bar{x}, \bar{p})$ is state-by-state Walrasian. Therefore, in equilibria in which agents are truthful, non-fully revealing CREE cannot be equilibrium allocations unless they are state-by-state Walrasian. The set of CREE allocations is neither a subset, nor a superset of the set of state-by-state CWE allocations. This observation will be useful to understand why, without measurability restrictions on allocations, CREE allocations may fail to be supportable as a Bayesian equilibrium outcome of the mechanism. We will show that although CREE allocations are the best measurable state-contingent allocations that agents can obtain, given the prices that prevail; they may not be the best state-contingent allocations that agents can obtain. Non-fully revealing CREE allocations may fail to be state-by-state Constrained Walrasian. It is well known (for instance, see Laffont (1985)) that fully revealing REE are ex-post efficient since every allocation is a WE in the respective associated full information economy. However, non-fully revealing REE may not be ex-post efficient and thus not interim efficient. For private values environments, non-fully revealing REE are also state-by-state Walrasian.

Hence, without measurability restrictions imposed on state-contingent allocations, there are some economies for which CREE are not supportable as a Bayesian equilibrium outcome of the mechanism. Therefore, due to the properties of REE, measurability restrictions on allocations do not emerge from the strategic behavior of agents. The counterexample we will use below is based on that observation. We first show that in every economy $E \in \mathcal{E}$

\footnotetext{
${ }^{14}$ For instance if agent $i$ is of type $t_{i}$ both in state $t$ and $t^{\prime}, t \neq t^{\prime}$, by private values $u_{i}(\cdot, t)=u_{i}\left(\cdot, t^{\prime}\right)=u_{i}\left(\cdot, t_{i}\right)$. If $p_{t}=p_{t^{\prime}}$, by strict quasi-concavity, the bundles that maximize $u_{i}$ over constrained budget sets defined by $p_{t}$ and $p_{t^{\prime}}$ are necessarily the same.
} 
with private values, the set of CREE is a subset of the set of equilibrium outcomes.

Proposition 3: In private values environment economies, the set of CREE allocations is contained in the set of equilibrium outcomes.

Proof: Suppose $\left(p^{*}, x^{*}\right)$ is a CREE in economy $E \in \mathcal{E}$ and consider the following strategies.

Agents $i$, of type $t_{i}$, announce $\left(p^{*}, x^{*}, 1, \hat{\alpha}_{i}\left(t_{i}\right)\right)^{i}$ where $\hat{\alpha}_{i}\left(t_{i}\right)=t_{i} \forall t_{i} \in T_{i}$, i.e. agents are truthful.

We claim that these strategies are equilibrium strategies of the game $(\Gamma, E)$.

It is clear that a unilateral deviation triggering rule 3 is not profitable since every CREE allocation is ex-post individually rational in private values environments. Now, can an agent gain by triggering rule 2? Since, for any agent $i \in N, x_{i}^{*}(t)$ is a maximal element in the constrained budget sets generated by $\bar{p}_{t}$ and $\omega_{i}$, for every $t \in T^{\star}$, by triggering rule 2 an agent can only obtain bundles that are at best utility equivalent to the bundles he was receiving at $x^{*}$. Notice that a deviation in type is not possible since the environment is of non-exclusive information: a unilateral deviation in type would trigger rule 3 . This cannot be profitable either, as seen above. Therefore, there are no profitable deviations from these strategies.

Q.E.D.

Theorem 1: There exists economies $E \in \mathcal{E}$ for which the set of Constrained REE is not contained in the set of Bayesian Equilibrium outcomes of $(\Gamma, E)$

Proof: The proof uses a counterexample. The economy $E$ we consider is a three agents economy that does not satisfy private values. It is identical to the one constructed in example 2 (see appendix).

$N=\{1,2,3\} . T_{1}=\left\{t_{1}, t_{1}^{\prime}\right\}, T_{2}=\left\{t_{2}\right\}$, and $T_{3}=\left\{t_{3}, t_{3}^{\prime}\right\}$. There are two states in $T^{\star}=\left\{t, t^{\prime}\right\}$ with $t=\left(t_{1}, t_{2}, t_{3}\right)$ and $t^{\prime}=\left(t_{1}^{\prime}, t_{2}, t_{3}^{\prime}\right)$. For agent 2, $q_{2}(s)=\frac{1}{2}, s=t, t^{\prime}$.

$$
\begin{array}{lll}
u_{1}\left(\cdot, t_{1}\right)=\frac{1}{2} \log x_{1}+\frac{1}{2} \log x_{2} & u_{1}\left(\cdot, t_{1}^{\prime}\right)=\frac{1}{3} \log x_{1}+\frac{2}{3} \log x_{2} & \omega_{1}=(1,1) \\
u_{2}(\cdot, t)=\frac{1}{3} \log x_{1}+\frac{2}{3} \log x_{2} & u_{2}\left(\cdot, t^{\prime}\right)=\frac{2}{3} \log x_{1}+\frac{1}{3} \log x_{2} & \omega_{2}=(1,1) \\
u_{3}\left(\cdot, t_{3}\right)=\frac{1}{3} \log x_{1}+\frac{2}{3} \log x_{2} & u_{3}\left(\cdot, t_{3}^{\prime}\right)=\frac{1}{2} \log x_{1}+\frac{1}{2} \log x_{2} & \omega_{3}=(1,1)
\end{array}
$$

There exists a non-revealing Constrained REE in this economy. It is given by the following price-allocation pair: 


$$
\begin{aligned}
& p_{t}=p_{t^{\prime}}=\left(1, \frac{5}{4}\right) \\
& x(t)=\left(\left(\frac{9}{8}, \frac{9}{10}\right) ;\left(\frac{9}{8}, \frac{9}{10}\right) ;\left(\frac{3}{4}, \frac{6}{5}\right)\right) \\
& x\left(t^{\prime}\right)=\left(\left(\frac{3}{4}, \frac{6}{5}\right) ;\left(\frac{9}{8}, \frac{9}{10}\right) ;\left(\frac{9}{8}, \frac{9}{10}\right)\right) .
\end{aligned}
$$

Since agents 1 and 3 receive different bundles across states, if $x$ is an equilibrium outcome of the mechanism, agents have to be truthful. So, suppose we consider the strategies given in the previous proposition. Agent 2 has a profitable deviation because the mechanism does not impose measurability restrictions on the allocations announced. As seen in example 2, allocation $x$ is not state-by-state Walrasian allocation at price $p=\left(1, \frac{5}{4}\right)$. The interim utility obtained from $x$ by agent 2 is $U_{2}\left(x \mid t_{2}\right)=0.002697515$. Agent 2 has a profitable deviation. He announces the highest integer, so as to be agent $i^{\star}$, and proposes the allocation,

$$
\begin{aligned}
x^{\prime}(t) & =((1.125,0.9) ;(0.75,1.2) ;(1.125,0.9)) \\
x^{\prime}\left(t^{\prime}\right) & =((0.75,1.2) ;(1.5,0.6) ;(0.75,1.2)) .
\end{aligned}
$$

The allocation $x^{\prime}$ gives an interim utility of 0.027293 to agent 2. By using this deviation, agent 2 triggers rule 2 and is awarded $x_{2}^{\prime}(s)$ when $s=t, t^{\prime}$ is reported. This is an interim profitable deviation for agent 2 .

Q.E.D.

What goes wrong for the inclusion of CREE in the set of equilibrium outcomes comes from non-fully revealing CREE in non-private values environments. This is due to the properties of such allocations. Measurability restrictions proper to CREE do not arise from the strategic behavior of agents. In fact, a non-fully revealing CREE allocation can typically arise as equilibrium only through the use of deceptions, unless it is state-by-state Walrasian. If utility functions are strictly quasi-concave, then no non-fully revealing CREE that is not state-by-state Walrasian can be a Bayesian equilibrium outcome.

An explanation for this is the following. At a REE, the only information that an agent obtains, on top of his own private information, is the one contained in the equilibrium prices. In the mechanism we use, on the other hand, there is a higher degree of centralization: an uninformed consumer may propose an allocation based on information that he does not have, even after observing the aggregate trade or the equilibrium prices. This makes sense here because information is non-exclusive. The mechanism can easily extract the information held by the other individuals. 
As a consequence, in order to obtain achievability of the CREE correspondence, we need to impose strong restrictions on the behavior of agents: measurability restrictions on allocations proper to CREE should be incorporated in the outcome function. By doing so, the deviation constructed in the counterexample is no longer possible. An agent $i$ would be restricted, in rule 2, to ask for state-contingent bundles that are measurable with respect to $\bar{p}$, that is state-contingent bundles for which if $p_{\left(t_{i}, t_{-i}\right)}=p_{\left(t_{i}, t_{-i}^{\prime}\right)}$, then $x_{i}\left(t_{i}, t_{-i}\right)=x_{i}\left(t_{i}, t_{-i}^{\prime}\right)$.

\subsection{Achieving and implementing the CREE Correspon- dence}

We incorporate in the mechanism the measurability restrictions on allocations that were introduced in item 2) in the definition of CREE.

\section{The Mechanism $\Gamma^{\prime}$ :}

Agents simultaneously announce a quadruple $\left(x, p, n, t_{i}\right)^{i} \in \mathbf{A} \times \mathbf{P} \times \mathbb{N} \times T_{i}$.

The outcome function is:

Rule 1: If the collection of types reported $s$ is compatible, $(x, p)^{i}=(\bar{x}, \bar{p})$ for each agent $i \in N$ and

1) $\bar{p}_{t} \cdot \bar{x}_{i}(t)=\bar{p}_{t} \cdot \omega_{i} \forall i \in N, \forall t \in T^{\star}$, and $\sum_{i} \bar{x}_{i}(t)=\bar{\omega}$ for every $t \in T^{\star}$,

2) $\forall i \in N, \forall t_{i} \in T_{i}, \bar{p}_{\left(t_{-i}, t_{i}\right)}=\bar{p}_{\left(t_{-i}^{\prime}, t_{i}\right)}$ for $t_{-i} \neq t_{-i}^{\prime} \Rightarrow \bar{x}_{i}(t)=\bar{x}_{i}\left(t^{\prime}\right)$,

then $\bar{x}(s)$ is implemented.

Rule 2: If the collection of types $s$ reported is compatible, $(x, p)^{j}=(\bar{x}, \bar{p})$ $\forall j \neq i^{\star}$ where $i^{\star}=\min \left\{i \in N: n^{i} \geq n^{j} \forall j \in N\right\}$ and if

1) $(\bar{x}, \bar{p})$ satisfies the conditions presented in rule 1

2) $p^{i^{\star}}=\bar{p}$

3) $x^{i^{\star}} \neq \bar{x}$

4) for agent $i^{\star}, \forall t_{i^{\star}} \in T_{i^{\star}}, \bar{p}_{\left(t_{-i^{\star}}, t_{i^{\star}}\right)}=\bar{p}_{\left(t_{-i^{\star}}^{\prime}, t_{i^{\star}}\right)}$ for $t_{-i^{\star}} \neq t_{-i^{\star}}^{\prime} \Rightarrow x_{i^{\star}}^{i^{\star}}(t)=$ $x_{i^{\star}}^{i^{\star}}\left(t^{\prime}\right)$

5) $\bar{p}_{t} \cdot x_{i^{\star}}^{i^{\star}}(t)=\bar{p}_{t} \cdot \omega_{i^{\star}} \forall t \in T^{\star}$

6) $x_{i^{\star}}^{i^{\star}}(t) \leq \bar{\omega} \forall t \in T^{\star}$

Then agent $i^{\star}$ gets $x_{i^{\star}}^{i^{\star}}(s)$ and agents $j \neq i^{\star}$ get 0 (and the rest of the goods is thrown away).

Rule 3: For all other cases, everybody receives their endowment, except agent $k^{\star}=\max \left\{k \in N: n^{k} \leq n^{j} \forall j \in N\right\}$ who receives 0 . 
Proposition 4: For every $E \in \mathcal{E}$, the set of Constrained $R E E$ allocations is contained in the set of Bayesian Equilibrium outcomes of $\left(\Gamma^{\prime}, E\right)$.

Proof: Assume $\left(x^{*}, p^{*}\right) \in C R E E(E)$. Then the following strategies support $x^{*}$ as a Bayesian Equilibrium allocation rule of the game form $\left(\Gamma^{\prime}, E\right)$ :

Agents $i$ announce $\left(p^{*}, x^{*}, 1, \hat{\alpha}_{i}\left(t_{i}\right)\right)^{i}$ where $\hat{\alpha}_{i}\left(t_{i}\right)=t_{i} \forall t_{i} \in T_{i}$-i.e. agents are truthful.

We claim that these strategies are equilibrium strategies. For all $t \in T^{\star}$, reported, the outcome is $x^{*}(t)$ and it is given by rule 1 . It is clear that a unilateral deviation triggering rule 3 is not profitable since any CREE is at least interim individually rational (and in fact is ex-post individually rational in the case of private values). Now, can an agent gain by triggering rule 2 ? Since $x^{*}$ is maximal -given the measurability restrictions - in the budget sets generated by $p^{*}$ and individual endowments, by triggering rule 2 , an agent can only reach measurable bundles that are at best interim utility equivalent to the bundles he was receiving at $x^{*}$. Notice that a deviation in type is not profitable since the environment is of non-exclusive information: a unilateral deviation in type would trigger rule 3 . Therefore, there are no profitable deviations from these strategies. We conclude that every Constrained REE is supportable in a Bayesian equilibrium using the above strategies.

Q.E.D.

Theorem 2: The normal form mechanism $\Gamma^{\prime}$ globally implements the CREE correspondence in Bayesian Equilibrium in the class of economies $\mathcal{E}$.

Proof: Given proposition 4 above, we only need to show that $B E\left(\Gamma^{\prime}, E\right) \subseteq$ $C R E E(E)$. Precisely, what we need to show is that if $\sigma$ is a Bayesian Equilibrium of $\left(\Gamma^{\prime}, E\right)$, then $g(\sigma) \in C R E E(E)$. Suppose $\sigma$ is a Bayesian Equilibrium and $g(\sigma)=a$. The proof is divided in a series of lemmas.

Lemma 8: For every $\alpha(\alpha=\hat{\alpha}$ or $\alpha \neq \hat{\alpha}), \nexists t \in T^{\star}$ such that $a(\alpha(t))$ comes from rule 3

Proof: Identical to the proof of lemma 4. A consequence of this lemma is that type-reports should always be compatible.

Lemma 9: For every compatible $\alpha(\alpha=\hat{\alpha}$ or $\alpha \neq \hat{\alpha}), \nexists t \in T^{\star}$ such that $a(\alpha(t))$ comes from rule 2.

Proof: Identical to the proof of lemma 5. A consequence of this lemma is that equilibrium outcomes are always given by rule 1 . In equilibrium, agents always agree on a state contingent price-allocation pair. 
Lemma 10: If agents are truthful (i.e. $\alpha=\hat{\alpha}),(\bar{x}, \bar{p})$ is a CREE.

Proof: Suppose not. The outcome is $\bar{x}(t)$ for every $t \in T^{\star}$ reported, and $(\bar{p}, \bar{x})$ is not a CREE. Notice that $\bar{x}$ is ex-post balanced, budget-balancing for every agent, in every state; and measurable - given $\bar{p}$ - for every agent $i$, for every $t_{i} \in T_{i}$. Therefore, item 3 ) in the definition of CREE is not satisfied. There exists an agent $i$, of type $t_{i}$, and a state-contingent bundle $y_{i} \neq \bar{x}_{i}$, measurable, feasible and budget-balancing given $\bar{p}$ such that

$$
\sum_{t_{-i} \in T_{-i}} q_{i}\left(t_{-i} \mid t_{i}\right) u_{i}\left(y_{i}(t), t\right)>\sum_{t_{-i} \in T_{-i}} q_{i}\left(t_{-i} \mid t_{i}\right) u_{i}\left(\bar{x}_{i}(t), t\right)
$$

Agent $i$, of type $t_{i}$, has a profitable deviation. By appropriately modifying the integer he announces, agent $i$ can make sure to become agent $i^{\star}$ for every $s \in T^{\star}$ for which $s_{i}=t_{i}$, and this with probability one. Thus he modifies his integer announcement and announce an allocation $y \neq \bar{x}$ with $y_{j}(t)=\frac{\bar{\omega}-y_{i}(t)}{n-1}$ for all $t \in T^{\star}$ and $y_{i}$ as identified above. Given the rules of the game, for every $s$, with $s_{i}=t_{i}$, reported, the outcome is given by rule 2 . Therefore, agent $i$, of type $t_{i}$, is awarded $y_{i}(s)$ for every $s$ reported with $s_{i}=t_{i}$ and thus obtains the expected utility identified above. This is a profitable deviation. A contradiction.

Lemma 11: For all compatible deception $\alpha,(\bar{x} \circ \alpha, \bar{p} \circ \alpha)$ is a CREE.

Proof: The proof is divided in two cases.

Case 1: $\alpha(t)=s \forall t \in T^{\star}$, i.e. agents play a constant deception. $\bar{x}(\alpha(t))=\bar{x}(s)$ and $\bar{p}(\alpha(t))=\bar{p}_{s} \forall t \in T^{\star}$. Suppose by way of contradiction that $\left(\bar{x}(s), \bar{p}_{s}\right)$ is not a CREE. Notice that $\bar{x}$ is ex-post balanced, budgetbalancing for every agent, in every state; and measurable -given $\bar{p}$ - for every agent $i$, for every $t_{i} \in T_{i}$. Therefore, item 3) in the definition of CREE is not satisfied. There exists an agent $i$, of type $t_{i}$, with $\alpha_{i}\left(t_{i}\right)=s_{i}$, and a bundle $y_{i}(s) \neq \bar{x}_{i}(s)$, ex-post feasible and budget-balancing at $\bar{p}_{s}$ such that

$$
\sum_{t_{-i} \in T_{-i}} q_{i}\left(t_{-i} \mid t_{i}\right) u_{i}\left(y_{i}(s), t\right)>\sum_{t_{-i} \in T_{-i}} q_{i}\left(t_{-i} \mid t_{i}\right) u_{i}\left(\bar{x}_{i}(s), t\right)
$$

Agent $i$, of type $t_{i}$, has a profitable deviation. By appropriately modifying the integer he announces, agent $i$ can make sure to become agent $i^{\star}$. He modifies his integer announcement and announce an allocation $y \neq \bar{x}$ along with $\bar{p}$. The allocation $y$ is constructed as follows. In allocation $y, \bar{x}_{i}(s)$ is replaced by the bundle $y_{i}(s)$ identified above. For $j \neq i, y_{j}(s)=\frac{\bar{\omega}-y_{i}(s)}{n-1}$. In 
order to satisfy measurability restrictions on $y_{i}$, if $\bar{p}(s)=\bar{p}\left(s^{\prime}\right)$ for $s^{\prime} \neq s$, with $s_{i}^{\prime}=s_{i}$ (where $\left.s_{i}=\alpha_{i}\left(t_{i}\right)\right)$, then $y_{i}\left(s^{\prime}\right)=y_{i}(s)$. For all states $s^{\prime} \neq s$ with $\alpha_{i}\left(t_{i}\right) \neq s_{i}^{\prime}, y_{i}\left(s^{\prime}\right)=\bar{x}_{i}\left(s^{\prime}\right)$. Again, for simplicity, $y_{j}\left(s^{\prime}\right)=\frac{\bar{\omega}-y_{i}\left(s^{\prime}\right)}{n-1} \forall j \neq i$, $\forall s^{\prime} \neq s$.

Given the rules of the game, for every $s$ reported, with $s_{i}=t_{i}$, the outcome is given by rule 2 . Therefore, agent $i$, of type $t_{i}$, is awarded $y_{i}(s)$ for every $\alpha(t)=\left(\ldots, \alpha_{i}\left(t_{i}\right), \ldots\right)$ reported with $\alpha_{i}\left(t_{i}\right)=s_{i}$ and thus obtains the expected utility identified above. This is a profitable deviation. A contradiction.

Case 2: $\alpha$ is a non-constant compatible deception. Suppose $(\bar{x}, \bar{p})$ is announced, and the compatible deception $\alpha$ is used. The equilibrium allocation rule is $\bar{x}_{\alpha}$ with price $\bar{p}_{\alpha}$. Suppose by way of contradiction that $\left(\bar{x}_{\alpha}, \bar{p}_{\alpha}\right)$ is not a CREE. Notice that since $\bar{x}$ is a measurable allocation with respect to $\bar{p}$, it implies that $\bar{x}_{\alpha}$ is measurable with respect to $\bar{p}_{\alpha}$. Now, since $\bar{x}$ is ex-post balanced and budget-balancing for every agent, in every state, condition 3) in the definition of CREE cannot be satisfied. There exists an agent $i$, of type $t_{i}$, and a state-contingent bundle $y_{i}$, measurable, feasible and budget-balancing given $\bar{p}_{\alpha}$, such that

$$
\sum_{t_{-i} \in T_{-i}} q_{i}\left(t_{-i} \mid t_{i}\right) u_{i}\left(y_{i}(t), t\right)>\sum_{t_{-i} \in T_{-i}} q_{i}\left(t_{-i} \mid t_{i}\right) u_{i}\left(\bar{x}_{i}(\alpha(t), t) .\right.
$$

Agent $i$ has a profitable deviation. By appropriately modifying the integer he announces, agent $i$ can make sure to become agent $i^{\star}$ for every state $s \in T^{\star}$, reported for which $\alpha_{i}\left(t_{i}\right)=s_{i}$. Thus he modifies his integer announcement and announce an allocation $z \neq \bar{x}$ along with $\bar{p}$. The allocation $z$ is constructed as follows.

The allocation $z$ is constructed so that $z_{i}(\alpha(t))=y_{i}(t) \forall \alpha(t)$, such that $\alpha(t)=s$ and $\alpha_{i}\left(t_{i}\right)=s_{i}$. Given $\alpha(t)=s$ with $\alpha_{i}\left(t_{i}\right)=s_{i}$, if $\bar{p}_{s^{\prime}}=\bar{p}_{s}$ with $s^{\prime} \neq s$ and $\alpha_{i}\left(t_{i}\right)=s_{i}^{\prime}$, then $z_{i}\left(s^{\prime}\right)=z_{i}(s)=y_{i}(t)$ by measurability. Now, for states $s$ such that $\alpha_{i}\left(t_{i}\right) \neq s_{i}, z_{i}(s)=\bar{x}_{i}(s)$. For every agent $j \neq i$, for every $t \in T^{\star}, z_{j}(t)=\frac{\bar{\omega}-z_{i}(t)}{n-1}$.

The state-contingent bundles $z_{i}$ are measurable with respect to $\bar{p}$. To summarize, the construction we have just done for agent $i$ is:

$z_{i}(s)=\bar{x}_{i}(s)$ for all $s$ such that $\alpha_{i}\left(t_{i}\right) \neq s_{i}$.

$z_{i}(s)=y_{i}(t)$ for all $s$ for which $\alpha(t)=s$ and $\alpha_{i}\left(t_{i}\right)=s_{i}$.

$z_{i}\left(s^{\prime}\right)=z_{i}(s)$ for all $s^{\prime}$ such that $\bar{p}_{s^{\prime}}=\bar{p}_{s}, s^{\prime} \neq \alpha(t) \forall t \in T^{\star}$, and $\alpha_{i}\left(t_{i}\right)=s_{i}^{\prime}$. 
Hence, an ex-post feasible, budget balancing and measurable allocation $z$ for agent $i$ of type $t_{i}$, can be constructed. It has the property that $z(\alpha(s))=$ $y(s) \forall \alpha(s)$ with $\alpha_{i}\left(t_{i}\right)=\alpha_{i}\left(s_{i}\right)$. Thus, allocation $z$ gives to agent $i$ of type $t_{i}$, the interim utility -given that $\alpha$ is played-

$$
U_{i}\left(z \circ \alpha \mid t_{i}\right)=U_{i}\left(y \mid t_{i}\right)>U_{i}\left(\bar{x} \circ \alpha \mid t_{i}\right) .
$$

The outcome is given by rule 2. Agent $i$, of type $t_{i}$ is awarded $z_{i}(\alpha(s))$, $\forall \alpha(s)$ for which $\alpha_{i}\left(s_{i}\right)=\alpha_{i}\left(t_{i}\right)$. He obtains the interim utility above. This is an interim profitable deviation. A contradiction with $m$ being a Bayesian Equilibrium.

The proof is now complete. We have shown that every CREE can be supported as a Bayesian Equilibrium outcome of the mechanism, and that every equilibrium allocation rule should be a CREE. We obtain a full implementation of the CREE correspondence.

Q.E.D.

The mechanism we initially designed for complete information describes well, to some extent, the Walrasian story. Agents report prices and allocations, and if what they agree on is not "optimal", one specific agent is allowed to maximize her utility over the budget set generated by the price vector collectively reported and her endowment, subject to the feasibility constraint. The extension of the CWE correspondence can coincide with the CREE correspondence.

We think that our result allows a better understanding of the gametheoretic foundations of CREE in the context of the implementation literature. It first shows that in order to at least achieve the Constrained REE correspondence with such a mechanism, the measurability restrictions on allocations cannot be dispensed with and should be imposed in the outcome function. Moreover, it also examines and establishes game-theoretic connections between WE and REE. It provides some support to the point of view that REE is an extension of WE to differential economies. However, in connection with the last section, this result is mitigated by the strong restrictions that needs to be imposed on the behavior of agents. In fact, is it so natural to impose measurability restrictions in our context?

To conclude this section, we present an example that illustrates the result. We construct an example of an economy with three agents and show that if a deception $\alpha$ is played and $(\bar{x} \circ \alpha, \bar{p} \circ \alpha)$ is not a constrained REE, then this allocation cannot be an equilibrium outcome. 


\section{Example 1:}

$N=\{1,2,3\}, T_{1}=\left(t_{1}, t_{1}^{\prime}\right), T_{i}=\left(t_{i}, t_{i}^{\prime}, t_{i}^{\prime \prime}\right), i=2,3$.

$T^{\star}=\left\{t^{1}, t^{2}, t^{3}, t^{4}, t^{5}\right\}$, with $t^{1}=\left(t_{1}, t_{2}, t_{3}\right), t^{2}=\left(t_{1}, t_{2}^{\prime}, t_{3}^{\prime}\right), t^{3}=\left(t_{1}, t_{2}^{\prime \prime}, t_{3}^{\prime \prime}\right)$, $t^{4}=\left(t_{1}^{\prime}, t_{2}^{\prime}, t_{3}\right)$ and $t^{5}=\left(t_{1}^{\prime}, t_{2}, t_{3}^{\prime}\right)$. Each agent has an endowment of 1 unit of each good. The states are equally likely.

$$
\begin{array}{ll}
u_{1}\left(\cdot, t^{1}\right)=\frac{1}{3} \log x_{1}+\frac{2}{3} \log x_{2} & u_{1}\left(\cdot, t^{2}\right)=\frac{1}{2} \log x_{1}+\frac{1}{2} \log x_{2} \\
u_{1}\left(\cdot, t^{3}\right)=\frac{2}{3} \log x_{1}+\frac{1}{3} \log x_{2} & u_{1}\left(\cdot, t_{1}^{\prime}\right)=\frac{1}{3} \log x_{1}+\frac{2}{3} \log x_{2} \\
u_{2}\left(\cdot, t_{2}\right)=\frac{1}{2} \log x_{1}+\frac{1}{2} \log x_{2} & u_{2}\left(\cdot, t_{2}^{\prime}\right)=\frac{1}{3} \log x_{1}+\frac{2}{3} \log x_{2} \\
u_{2}\left(\cdot, t_{2}^{\prime \prime}\right)=\frac{2}{3} \log x_{1}+\frac{1}{3} \log x_{2} & u_{3}\left(\cdot, t_{3}\right)=\frac{1}{3} \log x_{1}+\frac{2}{3} \log x_{2} \\
u_{3}\left(\cdot, t_{3}^{\prime}\right)=\frac{1}{2} \log x_{1}+\frac{1}{2} \log x_{2} & u_{3}\left(\cdot, t_{3}^{\prime \prime}\right)=\frac{2}{3} \log x_{1}+\frac{1}{3} \log x_{2}
\end{array}
$$

\section{Consider the following REE:}

$$
\begin{array}{ll}
p_{\left(t_{1}, t_{2}, t_{3}\right)}=p_{t^{1}}=\left(1, \frac{11}{7}\right) & x\left(t^{1}\right)=\left(\left(\frac{6}{7}, \frac{12}{11}\right) ;\left(\frac{9}{7}, \frac{9}{11}\right) ;\left(\frac{6}{7}, \frac{12}{11}\right)\right) \\
p_{\left(t_{1}, t_{2}^{\prime}, t_{3}^{\prime}\right)}=p_{t^{2}}=\left(1, \frac{5}{4}\right) & x\left(t^{2}\right)=\left(\left(\frac{9}{8}, \frac{9}{10}\right) ;\left(\frac{3}{4}, \frac{6}{5}\right) ;\left(\frac{9}{8}, \frac{9}{10}\right)\right) \\
p_{\left(t_{1}, t_{2}^{\prime \prime}, t_{3}^{\prime \prime}\right)}=p_{t^{3}}=\left(1, \frac{1}{2}\right) & x\left(t^{3}\right)=((1,1) ;(1,1) ;(1,1)) \\
p_{\left(t_{1}^{\prime}, t_{2}^{\prime}, t_{3}\right)}=p_{t^{4}}=(1,2) & x\left(t^{4}\right)=((1,1) ;(1,1) ;(1,1)) \\
p_{\left(t_{1}^{\prime}, t_{2}, t_{3}^{\prime}\right)}=p_{t^{5}}=\left(1, \frac{5}{4}\right) & x\left(t^{5}\right)=\left(\left(\frac{3}{4}, \frac{6}{5}\right) ;\left(\frac{9}{8}, \frac{9}{10}\right) ;\left(\frac{9}{8}, \frac{9}{10}\right)\right)
\end{array}
$$

Suppose agents announce $(x, p, 1)$, rule 1 applies and they play the following deception:

$$
\begin{array}{llll}
\text { Agent 1 } & \alpha_{1}\left(t_{1}\right)=t_{1}^{\prime} & \alpha_{1}\left(t_{1}^{\prime}\right)=t_{1} & \\
\text { Agent 2 } & \alpha_{2}\left(t_{2}\right)=t_{2}^{\prime} & \alpha_{2}\left(t_{2}^{\prime}\right)=t_{2} & \alpha_{2}\left(t_{2}^{\prime \prime}\right)=t_{2}^{\prime} \\
\text { Agent 3 } & \alpha_{3}\left(t_{3}\right)=t_{3} & \alpha_{3}\left(t_{3}^{\prime}\right)=t_{3}^{\prime} & \alpha_{3}\left(t_{3}^{\prime \prime}\right)=t_{3}
\end{array}
$$

This generates the following compatible deception $\alpha$ :

$\alpha\left(t^{1}\right)=t^{4}, \alpha\left(t^{2}\right)=t^{5}, \alpha\left(t^{3}\right)=t^{4}, \alpha\left(t^{4}\right)=t^{1}$ and $\alpha\left(t^{5}\right)=t^{2}$.

The allocation rule generated by $\alpha$ is $(x \circ \alpha, p \circ \alpha)$,

$$
\begin{aligned}
& p_{\alpha\left(t_{1}, t_{2}, t_{3}\right)}=p_{\alpha\left(t^{1}\right)}=(1,2) \quad x\left(\alpha\left(t^{1}\right)\right)=((1,1) ;(1,1) ;(1,1)) \\
& p_{\alpha\left(t_{1}, t_{2}^{\prime}, t_{3}^{\prime}\right)}=p_{\alpha\left(t^{2}\right)}=\left(1, \frac{5}{4}\right) \quad x\left(\alpha\left(t^{2}\right)\right)=\left(\left(\frac{3}{4}, \frac{6}{5}\right) ;\left(\frac{9}{8}, \frac{9}{10}\right) ;\left(\frac{9}{8}, \frac{9}{10}\right)\right) \\
& p_{\alpha\left(t_{1}, t_{2}^{\prime \prime}, t_{3}^{\prime \prime}\right)}=p_{\alpha\left(t^{3}\right)}=(1,2) \quad x\left(\alpha\left(t^{3}\right)\right)=((1,1) ;(1,1) ;(1,1)) \\
& p_{\alpha\left(t_{1}^{\prime}, t_{2}^{\prime}, t_{3}\right)}=p_{\alpha\left(t^{4}\right)}=\left(1, \frac{11}{7}\right) \quad x\left(\alpha\left(t^{4}\right)\right)=\left(\left(\frac{6}{7}, \frac{12}{11}\right) ;\left(\frac{9}{7}, \frac{9}{11}\right) ;\left(\frac{6}{7}, \frac{12}{11}\right)\right) \\
& p_{\alpha\left(t_{1}^{\prime}, t_{2}, t_{3}^{\prime}\right)}=p_{\alpha\left(t^{5}\right)}=\left(1, \frac{5}{4}\right) \quad x\left(\alpha\left(t^{5}\right)\right)=\left(\left(\frac{9}{8}, \frac{9}{10}\right) ;\left(\frac{3}{4}, \frac{6}{5}\right) ;\left(\frac{9}{8}, \frac{9}{10}\right)\right)
\end{aligned}
$$

Consider agent 1 , of type $t_{1}$. The allocation $x \circ \alpha$ gives him the following expected utility of $U_{1}\left(x \circ \alpha \mid t_{1}\right)=-0.0228$. Therefore, $x \circ \alpha$ cannot be a CREE since it is not even interim individually rational for agent 1 , of type $t_{1}$. Construct the following measurable bundles over states $t^{1}, t^{2}$ and $t^{3}$, given $p \circ \alpha$; feasible and budget-balancing at prices $p_{\alpha\left(t^{1}\right)}, p_{\alpha\left(t^{3}\right)}, p_{\alpha\left(t^{3}\right)}$ : 


$$
y_{1}\left(t^{1}\right)=\left(\frac{3}{2}, \frac{3}{4}\right) \quad y_{1}\left(t^{2}\right)=\left(\frac{9}{8}, \frac{9}{10}\right) \quad y_{1}\left(t^{3}\right)=\left(\frac{3}{2}, \frac{3}{4}\right)
$$

The interim utility obtained from these bundles by agent 1 , of type $t_{1}$, is $0.018>-0.0228$. Therefore, there exists measurable bundles, given $p \circ \alpha$, that agent 1 , of type $t_{1}$, would prefer to getting $x \circ \alpha$. Agent 1 , of type $t_{1}$ has a profitable deviation. He can construct the following measurable allocation $z \neq x,-$ now, measurable given $p$. We construct the allocation in such a way that it is actually measurable for every agent. Given rule 2, we need only construct it so that the bundles that agent $i^{\star}$ receives are measurable with respect to $p$.

$$
\begin{array}{ll}
p_{\left(t_{1}, t_{2}, t_{3}\right)}=p_{t^{1}}=\left(1, \frac{11}{7}\right) & z\left(t^{1}\right)=x\left(t^{1}\right)=\left(\left(\frac{6}{7}, \frac{12}{11}\right) ;\left(\frac{9}{7}, \frac{9}{11}\right) ;\left(\frac{6}{7}, \frac{12}{11}\right)\right) \\
p_{\left(t_{1}, t_{2}^{\prime}, t_{3}^{\prime}\right)}=p_{t^{2}}=\left(1, \frac{5}{4}\right) & z\left(t^{2}\right)=x\left(t^{2}\right)=\left(\left(\frac{9}{8}, \frac{9}{10}\right) ;\left(\frac{3}{4}, \frac{6}{5}\right) ;\left(\frac{9}{8}, \frac{9}{10}\right)\right) \\
p_{\left(t_{1}, t_{2}^{\prime \prime}, t_{3}^{\prime \prime}\right)}=p_{t^{3}}=\left(1, \frac{1}{2}\right) & z\left(t^{3}\right)=x\left(t^{3}\right)=((1,1) ;(1,1) ;(1,1)) \\
p_{\left(t_{1}^{\prime}, t_{2}^{\prime}, t_{3}\right)}=p_{t^{4}}=(1,2) & z\left(t^{4}\right)=y\left(t^{1}\right)=y\left(t^{3}\right)=\left(\left(\frac{3}{2}, \frac{3}{4}\right) ;\left(\frac{3}{4}, \frac{9}{8}\right),\left(\frac{3}{4}, \frac{9}{8}\right)\right) \\
p_{\left(t_{1}^{\prime}, t_{2}, t_{3}^{\prime}\right)}=p_{t^{5}}=\left(1, \frac{5}{4}\right) & z\left(t^{5}\right)=y\left(t^{2}\right)=\left(\left(\frac{9}{8}, \frac{9}{10}\right) ;\left(\frac{3}{4} ; \frac{6}{5}\right) ;\left(\frac{9}{8}, \frac{9}{10}\right)\right)
\end{array}
$$

Agent 1 can announce a higher integer and be agent $i^{\star}$, the agent with the highest integer. Announcing allocation $z$ constructed above, agent 1, of type $t_{1}$, triggers rule 2 and obtains bundles $z_{1}(\alpha(s))=y_{1}(s)$ for $s=t^{1}, t^{2}, t^{3}$. This gives him the expected utility calculated above. Therefore, the deviation is profitable.

\subsection{Conclusion}

In this paper, we have taken a different approach than what is usually studied in the implementation literature. Using an elementary mechanism, similar to the one constructed in DSV, we followed an approach that had been used in the recent literature on Shapley-Shubik strategic market games. The goal was to understand if one could draw game-theoretic connections between WE and REE using an elementary mechanism.

By extending the mechanism we designed, the properties of equilibrium allocation rules were very close to the description of CREE allocations. However, we first showed that the measurability restrictions on allocations proper to REE do not emerge naturally from the behavior of agents: there exists economies for which the set of CREE allocations is not contained in the set of Bayesian equilibrium outcomes of the mechanism. Next, by imposing these measurability restrictions in the outcome function, the mechanism 
globally implemented the CREE correspondence. The result provides support for REE as an extension of WE to economies with differential information. However, this conclusion is obtained at the price of strong restrictions on the behavior of agents. Is it so natural to impose measurability in our context? In addition, the result in the last section can be viewed as an interesting result on its own since it provides an appealing mechanism to fully Bayesian implement the CREE correspondence.

Several extensions of this work can be considered. First, what would happen to our conclusions if we followed an approach similar to the one used in Forges and Minelli (1997)? That is, instead of modifying the mechanism we had for complete information, we could keep it as it is and add to it a communication stage in which agents privately report their types to the mediator and the mediator in turn reports a price -if the collection of report is compatible. We conjecture that the CREE correspondence is obtained as self-fulfilling equilibria of our mechanism. However, notice that in each selffulfilling equilibrium, agents are truthful. Like in Forges and Minelli (1997), we would have some unwanted Bayesian equilibria. On the other hand, our result in the last section is a full Bayesian implementation result of the CREE correspondence.

Finally, we could repeat the game several periods and keep the message spaces unchanged when switching from complete to incomplete information. By doing so, we would explicitly incorporate issue of information transmission in the model. A natural question that would arise is to analyze the difference between the game being repeated a finite number of periods and infinitely. We leave answers to these questions open for future work.

\section{References}

1. Blume L., Easley D., 1990. "Implementation of Walrasian Expectations Equilibria." Journal of Economic Theory 51, 207-227.

2. Codognato G., Ghosal S., 2003. "Self-Fulfilling Mechanisms and Rational Expectations in Market with a Continuum of Traders." Forthcoming in Journal of Mathematical Economics.

3. Dubey P., Geanakoplos J., Shubik M., 1987. "The Revelation of Information in Strategic Market Games, a Critique of Rational Expectations Equilibrium." Journal of Mathematical Economics 16, 105-137

4. Dutta B., Sen A., Vohra R., 1995. "Nash Implementation through Elementary Mechanisms in Economic Environments." Review of Economic Design 1, 173-203. 
5. Forges F., Minelli E., 1997. "Self-fulfilling mechanisms and Rational Expectations." Games and Economic Behavior 75, 388-406

6. Gale D., 1987. "Limit Theorems for Market with Sequential Bargaining." Journal of Economic Theory 43, 20-54

7. Gottardi P., Serrano R., 2005. "Market Power and Information Revelation in Dynamic trading." Journal of the European Economic Association, forthcoming.

8. Holmström B., Myerson R., 1983. "Efficient and Durable Decision Rule with Incomplete Information." Econometrica 51, 1799-1819.

9. Hurwicz L., 1972. "On Informationally Decentralized Systems." in McGuire C.B, and Radner R. (eds), Decision and organization. Amsterdam: North-Holland, chapter 14.

10. Hurwicz L., 1979. "Outcomes Functions Yielding Walrasian and Lindhal Allocations at Nash Equilibrium Points." Review of Economic Studies 46, 217-225.

11. Hurwicz L., Maskin E. and Postlewaite A. 1995. "Feasible Nash Implementation." in Ledyard J.O. (ed), The Economics of Informational Decentralization. Complexity, Efficiency and stability. Kluwer Academic Publisher.

12. Jackson M., 1991. "Bayesian Implementation." Econometrica 59, 461-477.

13. Laffont J.J., 1985. "On the Welfare Analysis of Rational Expectations Equilibria with Asymmetric Information." Econometrica 53, 1-30

14. Maskin E., 1999. "Nash Equilibrium and Welfare Optimality." Review of Economic Studies 66, 23-38.

15. Palfrey T., Srivastava S., 1987. "On Bayesian Implementable Allocations." Review of Economic Studies 54, 193-208

16. Palfrey T., Srivastava S., 1989. "Implementation with Incomplete Information in Exchange Economies." Econometrica 57, 115-134

17. Postlewaite A., Schmeidler D., 1986. "Implementation in Differential Economies." Journal of Economic Theory 39, 14-33

18. Postlewaite A., Wettstein D., 1989. "Feasible and Continuous Implementation." Review of Economic Studies 56, 603-611.

19. Radner R., 1979. "Rational Expectations Equilibrium: Generic Existence and the Information Revealed by Prices." Econometrica 47, 655-678.

20. Schmeidler D., 1980. "Walrasian Analysis via Strategic Outcome Functions." Econometrica 48, 1585-1593. 
21. Serrano R., 2002. "Decentralized Information and the Walrasian Outcome: a Pairwise Meeting Market with Private Values." Journal of Mathematical Economics 38, 65-89

22. Wettstein D., 1990. "Continuous Implementation of Constrained Rational Expectations Equilibria." Journal of Economic Theory 52, 208-222.

23. Wolinsky A., 1990. "Information Revelation in a Market with Pairwise Meetings." Econometrica 58, 1-23.

\section{Appendix}

Proof of theorem 1:

We begin by showing that $C W(E) \subseteq N E(\Gamma, E)$

Suppose $x^{*} \in C W(E)$ with associated walrasian price vector $p^{*}$. Then the following strategies support $x^{*}$ as a Nash Equilibrium outcome of the game form $(\Gamma, E)$ :

Every agent $i$ announces $\left(x^{*}, p^{*}, 1\right)^{i}$.

The outcome $x^{*}$ is given by rule 1 . It is easy to see that there are no profitable deviation from these strategies. First, by unilaterally deviating and triggering rule 3, an agent can at best receive her endowment. Since Constrained Walrasian Equilibrium are individually rational, this is not profitable. Second, by announcing $x^{i} \neq x^{*}$, feasible and budget balancing at $p^{*}$, and the highest integer, any agent $i$ can become $i^{\star}$ and make the outcome to fall into rule 2. Since $\left(x^{*}, p^{*}\right)$ is a Constrained Walrasian equilibrium, any such $x^{i^{\star}}$ gives to agent $i, u_{i}\left(x_{i^{\star}}^{i^{\star}}\right) \leq u_{i}\left(x_{i^{\star}}^{*}\right)$. Therefore, $x_{i^{\star}}^{*} \in \arg \max _{B_{i^{\star}}\left(p^{*}\right)} u_{i^{\star}}\left(x_{i^{\star}}\right)$ for every $x_{i^{\star}} \leq \bar{\omega}$, thus agent $i^{\star}$ cannot gain by getting $x_{i^{\star}}^{\prime} \neq x_{i^{\star}}^{*}$ along the hyperplane with normal $p^{*}$.

Therefore, the proposed strategies constitute a Nash Equilibrium. $g(m)=$ $x^{*}$ and $x^{*} \in N E(\Gamma, E)$.

We prove now that $N E(\Gamma, E) \subseteq C W(E)$. What we need to show is that if $m$ is a Nash Equilibrium of $(\Gamma, E)$, then $g(m) \in C W(E)$. Suppose $m$ is a Nash Equilibrium such that $m_{i}=(x, p, n)^{i}$ and $g(m)=a$. The proof is divided in a series of lemma.

Lemma 1: There are no equilibrium in rule 3

Proof: Suppose not. Agent $k^{\star}$ receives 0. By modifying the integer he announced -and possibly his price announcement in order to keep the outcome in rule 3 - this agent can make sure, given the strategies of the other players, not to be agent $k^{\star}$ and therefore to receive his endowment. 
By strong monotonicity of preferences and since $\omega_{i}>0 \forall i \in N$, this is a profitable deviation. A contradiction.

Lemma 2: There are no equilibrium in rule 2

Proof: Suppose not. Every agent $j \neq i^{\star}$ receives 0 . By modifying the integer she announced, agent $j \neq i^{\star}$ can make sure not to receive 0 . Suppose she announces the highest integer. The outcome is now given by rule 3 and she receives her endowment. Since $\omega_{i}>0 \forall i \in N$ and preferences are strongly monotonic, this is a profitable deviation. A contradiction.

Lemma 3: $(\bar{x}, \bar{p})$ is a Constrained Walrasian Equilibrium

Proof: Suppose not. $(\bar{x}, \bar{p})$ is announced by all the agents, the equilibrium is given by rule 1 and $(\bar{x}, \bar{p})$ is not a Constrained Walrasian Equilibrium. By definition of a Constrained Walrasian Equilibrium, there exists an agent $i \in N$, and an allocation $x^{\prime} \in A$, with $\bar{p} \cdot x_{i}^{\prime}=\bar{p} \cdot \omega_{i}$ such that

$$
u_{i}\left(x_{i}^{\prime}\right)>u_{i}\left(\bar{x}_{i}\right)
$$

Agent $i$ has a profitable deviation. Agent $i$ announces the highest integer so as to be agent $i^{\star}$ and the allocation $x^{\prime}$. The outcome is then determined by rule 2. Given rule 2, agent $i=i^{\star}$ is awarded $x_{i^{\star}}^{\prime}$. This is a profitable deviation. A contradiction.

The proof is now complete. We have established existence of Nash equilibrium outcome that are constrained Walrasian, and then proved that every equilibrium outcome should be constrained Walrasian.

Q.E.D.

\section{Some Welfare properties of REE:}

Example 2: Constrained REE allocations may not be ex-post individually rational

$N=\{1,2,3\} . T_{1}=\left\{t_{1}, t_{1}^{\prime}\right\}, T_{2}=\left\{t_{2}\right\}$, and $T_{3}=\left\{t_{3}, t_{3}^{\prime}\right\}$. There are two states in $T^{\star}=\left\{t, t^{\prime}\right\}$ with $t=\left(t_{1}, t_{2}, t_{3}\right)$ and $t^{\prime}=\left(t_{1}^{\prime}, t_{2}, t_{3}^{\prime}\right)$

$$
\begin{array}{lll}
u_{1}\left(\cdot, t_{1}\right)=\frac{1}{2} \log x_{1}+\frac{1}{2} \log x_{2} & u_{1}\left(\cdot, t_{1}^{\prime}\right)=\frac{1}{3} \log x_{1}+\frac{2}{3} \log x_{2} & \omega_{1}=(1,1) \\
u_{2}(\cdot, t)=\frac{1}{3} \log x_{1}+\frac{2}{3} \log x_{2} & u_{2}\left(\cdot, t^{\prime}\right)=\frac{2}{3} \log x_{1}+\frac{1}{3} \log x_{2} & \omega_{2}=(1,1) \\
u_{3}\left(\cdot, t_{3}\right)=\frac{1}{3} \log x_{1}+\frac{2}{3} \log x_{2} & u_{3}\left(\cdot, t_{3}^{\prime}\right)=\frac{1}{2} \log x_{1}+\frac{1}{2} \log x_{2} & \omega_{3}=(1,1)
\end{array}
$$

and $q_{2}(s)=\frac{1}{2}, s=t, t^{\prime}$.

There exists a non-revealing Constrained REE in this economy. It is given by the following price-allocation pair: 


$$
\begin{aligned}
& p_{t}=p_{t^{\prime}}=\left(1, \frac{5}{4}\right) \\
& x(t)=\left(\left(\frac{9}{8}, \frac{9}{10}\right) ;\left(\frac{9}{8}, \frac{9}{10}\right) ;\left(\frac{3}{4}, \frac{6}{5}\right)\right) \\
& x\left(t^{\prime}\right)=\left(\left(\frac{3}{4}, \frac{6}{5}\right) ;\left(\frac{9}{8}, \frac{9}{10}\right) ;\left(\frac{9}{8}, \frac{9}{10}\right)\right)
\end{aligned}
$$

This allocation is not ex-post individually rational for agent 2 in state $t$. Receiving the endowment gives an ex-post utility of 0 to agent 2. However, it gives a utility of $u_{2}(x, t)=-0.02172$.

Example 3: Constrained REE allocations may not be state-by-stateWalrasian

Consider the economy described in example 2. Allocation $x$ is not stateby-state Walrasian at prices $p=\left(1, \frac{5}{4}\right)$. Obviously, since agent 1 and 3 are informed, every state-contingent bundles they would prefer are not affordable at $p$. But the constant bundle received by agent 2 does not correspond to what he would ask for in state $t$ and $t^{\prime}$, had he known the state. Consider state $t$. The (ex-post) Walrasian demand for agent 2 , at $p$, is $x_{2}^{\prime}(t)=\left(\frac{3}{4}, \frac{6}{5}\right)$. The same applies for state $t^{\prime}$ with $x_{2}^{\prime}\left(t^{\prime}\right)=\left(\frac{6}{5}, \frac{3}{4}\right)$. Agent 2 would obtain a strictly greater expected utility.

Example 4: Constrained REE allocations may not be interim efficient $N=\{1,2,3,4\} . \quad T_{1}=\left\{t_{1}, t_{1}^{\prime}\right\}, T_{2}=\left\{t_{2}, t_{2}^{\prime}\right\} T_{3}=\left\{t_{3}\right\}$, and $T_{4}=$ $\left\{t_{4}\right\}$. There are two states in $T^{\star}=\left\{t, t^{\prime}\right\}$ with $t=\left(t_{1}, t_{2}, t_{3}, t_{4}\right)$ and $t^{\prime}=$ $\left(t_{1}^{\prime}, t_{2}^{\prime}, t_{3}, t_{4}\right)$

$$
\begin{array}{ccc}
u_{1}\left(\cdot, t_{1}\right)=x & u_{1}\left(\cdot, t_{1}^{\prime}\right)=2 x & \omega_{1}=1 \\
u_{2}\left(\cdot, t_{2}\right)=2 x & u_{2}\left(\cdot, t_{2}^{\prime}\right)=x & \omega_{2}=1 \\
u_{3}(\cdot, t)=\sqrt{x} & u_{3}\left(\cdot, t^{\prime}\right)=\sqrt{2 x} & \omega_{3}=1 \\
u_{4}(\cdot, t)=\sqrt{2 x} & u_{4}\left(\cdot, t^{\prime}\right)=\sqrt{x} & \omega_{4}=1
\end{array}
$$

Agents 3 and 4 differ in their probability assessment over the states $t$ and $t^{\prime}$. For agent 2, $q_{2}(t)=\frac{1}{3}, q_{2}\left(t^{\prime}\right)=\frac{2}{3}$; while for agent $3, q_{3}(t)=\frac{2}{3}$ and $q_{3}\left(t^{\prime}\right)=\frac{1}{3}$ There exists a unique REE. It is non-revealing. Agents keep their endowments and $p=1$ in both state. Agents 1 and 2, being informed, do not wish to trade: individual rationality implies that they receive their endowment since there is only one good. However, this allocation is not interim efficient. Agent 3 and 4 could exploit the difference in their probability assessments over the state of the world. The allocation $x^{\prime}(t)=(1,1,0.9,1.1)$, $x^{\prime}\left(t^{\prime}\right)=(1,1,1.1,0.9)$ interim dominates allocation $x$. 